\title{
O SAMBA DE ENREDO CARIOCA E A DEMOCRACIA DELIBERATIVA
}

\author{
Galdino Luiz Ramos Júnior* \\ Jefferson Aparecido Dias ${ }^{* *}$
}

\section{Resumo:}

O objetivo do presente artigo é investigar o alcance do samba de enredo enquanto manifestação artística e instrumento de democracia deliberativa. As concepções de democracia representativa e participativa são relidas, bem como o Direito é concebido a partir do pluralismo jurídico e de forma intercultural. $\mathrm{O}$ samba de enredo funciona como aparato de crítica e alerta, além de mecanismo de reivindicações públicas, capazes de alterarem e mobilizarem os centros de poder, externando diferenças e as minorando. $\mathrm{O}$ artigo utiliza-se de método dedutivo, de uma pesquisa bibliográfica de cunho histórico e exploratório, bem como se desenvolve no formato analítico-descritivo.

Palavras-chave: Democracia deliberativa; Pluralismo jurídico; Direito intercultural; Samba de enredo

\section{THE CARIOCA SAMBA DE ENREDO AND THE DELIBERATIVE DEMOCRACY}

\begin{abstract}
:
The aim of this paper is to investigate the scope of samba de enredo as an artistic expression and an instrument of deliberative democracy. The conceptions of representative and participatory democracy are reread, as well as the Law is conceived from legal pluralism and in an intercultural way. The samba de enredo works as an apparatus of criticism and alert, as well as a mechanism of public demands, capable of altering and mobilizing the centers of power, expressing differences and reducing them. The article uses a deductive method, a bibliographic research of historical and exploratory nature, as well as being developed in an analyticaldescriptive format.
\end{abstract}

Keywords: Deliberative democracy; Legal pluralism; Intercultural law; Samba de enredo.

\section{INTRODUÇÃO}

Em sua natureza gregária, o ser humano, na busca incessante pelo suprimento de suas mais comezinhas necessidades, depara-se com escolhas individuais e coletivas a serem tomadas e que repercutirão no modelo de coletividade no qual está inserto.

“Unus homo, nullus homo". Homem só é homem nenhum.

\footnotetext{
* Mestre e Doutor em Direito pela UNIMAR (Universidade de Marília). Professor da UNIMAR (Universidade de Marília). Advogado.

** Doutor em Direitos Humanos e Desenvolvimento pela Universidade Pablo de Olavide, Sevilha (Espanha). Professor da UNIMAR (Universidade de Marília). Procurador da República.
} 
A aproximação entre os integrantes do todo social acaba por gerar interações múltiplas que, conforme se desenvolvem, podem ou implicarem na satisfação plena das finalidades almejadas por cada indivíduo, ou imporem conflitos de interesses que demandam a interferência de um órgão instrumentalizado hábil à pacificação social: o Estado.

A natureza jurídica do Estado, sem ingressar nas concepções filosóficas e doutrinárias aplicáveis, mostra-se, pelo menos com mais clareza e efetividade, na segunda metade do século XX, como de índole democrática, ou, pelo menos, dita democrática (tem-se exceções de regimes autoritários e, sub-repticiamente, antidemocráticos).

O objetivo será discutir e identificar qual espécie de democracia se observa nas coletividades, seu alcance e sua efetiva aplicação nos contatos sociais, seu exercício pelos cidadãos, direta ou indiretamente, através de representantes ou, até mesmo, por suas próprias condutas. Daí a necessidade de uma (re)leitura contemporânea da democracia enquanto espaço de exercício de poderes periférico e difuso, com ênfase na denominada democracia deliberativa que, para o presente trabalho, incluirá a democracia participativa, uma vez que não é possível deliberar sem antes participar.

A partir daí, a compreensão jurídica da temática passando por uma visão pluralista do Direito reveladora de um discurso que, sob o pretexto de manter a ordem e conservar as estruturas sociais, acaba institucionalizando a desigualdade e sufocando manifestações insurgentes, que visam à busca por alternativas de poder e multiplicidade de discurso.

A interculturalidade será apresentada neste trabalho, além do alcance comum de multiculturalismo (reconhecimento das diferenças entre povos, preservando-se o respeito por tais), mas sim como relação efetiva de entrelaçamento e choques, a partir do qual, a coexistência entre diversos e plurais transcende ao mero respeito e parte para necessárias polaridades e implicações, que fazem com que os analistas sociais, dentre eles o operador jurídico, busquem alternativas plausíveis para garantir, sem excluir a diversidade, fazendo, do ponto de vista da praxis, uma verdadeira democracia deliberativa; um direito não de vencedores e vencidos, mas sim, um direito humanizado e influenciado por suas contradições e limites.

A efetivação de uma democracia deliberativa nascida da cultura de um povo vem, aqui exemplificada, com o denominado samba de enredo. Espécie do gênero musical samba e base para o desenvolvimento da temática das conhecidas escolas de samba, o samba de enredo, ao longo da história do Brasil, sempre apresentou um viés indicativo de pensamentos e interesses das comunidades das quais nasceu. 
Desde já se esclarece que a análise dos sambas-de-enredo de Escolas de Samba do Grupo Especial do Rio de Janeiro não fecha os olhos a inúmeras interferências externas que, muitas vezes, levaram as agremiações carnavalescas a produzirem enredos comprometidos na manutenção do "status quo" conservador, além de se submeterem a influências ilícitas de patronos e mantenedores ligados a práticas ilegais.

O fato, porém, é que o samba de enredo é modelo cultural que transcende a musicalidade, servindo, além de outras formas de exteriorização artística, como democracia aplicada a partir do próprio ser humano integrante de um contexto social determinado.

Ao final, utilizando-se do método dedutivo e a partir de uma pesquisa bibliográfica de cunho histórico e exploratório, o trabalho desenvolve-se de forma analítico-descritiva, sistematizando-se normas e doutrinas aplicáveis, sem abrir mão de exame dialético dos pontos fulcrais de discussão, em especial as letras dos sambas de enredo e a sua vinculação com a democracia deliberativa, para demonstrar que reconhecer alternativas culturais como formas de implementação de democracia deliberativa é reconhecer um Direito transformador e implementador dos valores e princípios éticos que caracterizam um povo, sufragando suas garantias fundamentais, a partir da universalidade e complementariedade dos direitos humanos em suas gerações ou dimensões evolutivas. Este será o desafio.

\section{PLURALISMO JURÍDico E DEMOCRACIA DELIBERATIVA. ESPAÇOS NÃO OFICIAIS DE DIREITO}

É sabido que existe um discurso oficial que engessa o pensamento jurídico dentro de um formato hermético e adstrito ao direito posto, sendo necessário apontar caminhos plurais de reconhecimento de "espaços de oxigenação" que reconhecem o Direito como transformador de uma ordem pré-estabelecida, vertendo-a a uma alternativa para o desenvolvimento humano através da implementação de seus caros valores.

Só se pode admitir estes "espaços" de novos direitos, superando-se a concepção de direito estatal como a única ordem jurídica válida e eficaz.

Fala-se assim de um Direito que, necessariamente, não nasce do Estado através de seus poderes constituídos, mas sim da própria sociedade, através de movimentos intrínsecos, nem sempre organizados: um "estar-no-mundo". 
O estar-aí nunca é algo de fechado que há que sair para ir ter com o mundo; o Dasein já é sempre e constitutivamente relação com o mundo, antes de toda a distinção artificial entre sujeito e objeto. $\mathrm{O}$ conhecimento como interpretação não é o desenvolvimento e articulação das fantasias que o Dasein, como sujeito individual, possa ter sobre o mundo, mas, sim, a elaboração da constitutiva e originária relação com o mundo que o constitui (STRECK, 2004, p. 200-201).

A sociedade, muito além de representada por terceiros legitimados ao exercício de poderes constituídos, exerce, diretamente, tais poderes, ditando regras e princípios que informam a conduta dos aplicadores do Direito e a própria norma posta.

Há, pois, uma visão plural do fenômeno jurídico em sua essência humana e em seus limites abertos, repleto de "movimentos ecléticos" e passíveis de complementação pela própria experiência social.

É processo de reinvenção do Direito visto como mantenedor de um "status quo" para um Direito inovador e dinâmico que segue, instantaneamente (ou pelo menos pretende seguir), as nuances sociais. Joaquín Herrera Flores aponta a necessária visão reflexa de um Direito comprometido com a transformação da ordem posta:

[...] 2. Mas o pensamento crítico vai além disso. É um pensamento de combate. Deve, pois, desempenhar um forte papel de conscientização que ajude a lutar contra o adversário e a reforçar os próprios objetivos e fins. Quer dizer, deve ser eficaz com vistas à materialização (HERRERA FLORES, 2009, p. 62).

Um direito plural é um direito de combate. O bom combate. A luta diária que nasce do âmago social, onde os pelejadores são os reais construtores do Direito, não meros destinatários da norma.

Dentro de uma ótica de abertura e reconhecimento das diferenças em processo de trocas de experiências e interculturalidade, o Direito para ser comprometido com qualquer anseio de transformação social, demanda diversidade e pluralidade de concepções. Wolkmer esclarece:

Por consequência, repensar a questão do "pluralismo" nada mais é do que a tentativa de buscar outra direção ou outro referencial epistemológico que atenda à modernidade na virada do século $\mathrm{XX}$ e nos primórdios do novo milênio - tanto das Ciências Humanas quanto da Teoria Geral do Direito não acompanham as profundas transformações sociais e econômicas por que passam as sociedades políticas pós-industriais e as sociedades de industrialização tardia (WOLKMER, 2001, p. 170). 
São várias as vertentes de pluralismo. Podemos concebê-lo em aspectos sociológicos, econômicos, filosóficos, políticos (abordados mais adiante), jurídicos etc.... Tem-se em comum a ideia (ou ideologia) de superação de uma concepção monolítica, monista e central de poder social, reconhecendo outros "aspectos" de atuação coletiva.

O pluralismo jurídico, pois, nasce da necessidade comum de organização societária a partir da própria manifestação cultural da sociedade, hábil a se autodeterminar e influenciar o aparato estatal, oficial. O nascimento deste Direito não estatal, plural, parte de um fortalecimento de fontes acessórias ao Direito oficial, notadamente os costumes, a jurisprudência, os princípios gerais de direito e a doutrina.

O que se prega é uma leitura do fenômeno jurídico normativo a partir destas fontes alternativas à lei e que, pelo seu próprio dinamismo, emprega os valores da sociedade a partir do momento em que são reconhecidos pelo grupo, de forma democrática.

É, justamente, na visão de democracia que se pretende dar uma nova roupagem ao modelo democrático vigente no Estado moderno, o brasileiro no caso, possibilitando o exercício do pluralismo jurídico. Frise-se: exercício plural do Direito utilizando-se da democracia deliberativa como seu instrumental:

Assim, se estabelece um modelo de contraste com o liberalismo que pensa a deliberação apenas como normatização constitucional da soberania e não consegue dar vida ou espírito a uma soberania popular que continua constituindo a base do sistema democrático (AVRITZER, 2011).

Toda a concepção que pauta este trabalho é fulcrada na superação de modelos tradicionais que, sob o pretexto de conservação da ordem instituída, não permitem novos paradigmas a serem construídos a partir de experiências sociais não organizadas formalmente. A democracia que aqui se almeja é aquela que dá:

[...] às pessoas a oportunidade de chamar a atenção eficazmente para necessidades gerais e exigir a ação pública apropriada. A resposta do governo ao sofrimento intenso do povo frequentemente depende da pressão exercida sobre esse governo, e é nisso que o exercício dos direitos políticos (votar, criticar, protestar etc) pode realmente fazer diferença (SEN, 2016, p. 199).

Apregoa-se, assim, um modelo de "democracia deliberativa", que, no dizer de Leonardo Avritzer (2011), é: “[...] claramente dependente de um processo público de comunicação, 
através do qual a sociedade debate, argumenta e toma decisões, sobre questões práticas relevantes".

A democracia deliberativa, como a própria etimologia da palavra indica, representa reflexão, discussão, apontamento, enfim, busca por um fim determinado a partir da análise de um momento social. ${ }^{1}$

Deliberar é muito mais do que exercitar um poder através de seus representantes ou por instrumentos pré-moldados pelo ordenamento jurídico. Deliberar é raciocinar sobre necessidades sensíveis de uma comunidade que as percebe, não a partir de outros interlocutores do discurso social, mas, sim, a partir da própria experiência vivida. Allebrandt e Agostini lecionam sobre democracia deliberativa: "Para essa corrente, democracia organiza-se em torno de um ideal de justificação política: justificar o exercício do poder político coletivo é proceder com base na argumentação pública livre entre iguais" (ALLEBRANDT; AGOSTINI, 2015).

A deliberação o é pelo integrante coletivo, funcionando como instrumental de "praxis" para se atingir um objetivo maior. Uma necessidade sentida e buscada. A democracia deliberativa é essencialmente pluralista e culturalizante.

Pluralista, pois, reconhece espaços não oficiais de poder político e, por consequência, de poder jurídico. Espaços não tradicionais de Direito, através dos quais, a sociedade interfere, diretamente, na condução de seu destino. Neste contexto democrático que o elemento cultura surge com sensível força. Os aspectos culturais de uma sociedade refletem suas instituições e estas suas prementes necessidades. A cultura emerge como elemento emancipador e diretivo ao processo que dita os caminhos coletivos a serem seguidos.

A democracia deliberativa, pois, é a cultura se instrumentalizando através de um poder político nascido do seio social; das reflexões e críticas da pessoa humana em suas divergências e pluralidades.

\section{INTERCULTURALIDADE E DIREITO. FORÇAS IMPLICATIVAS}

\footnotetext{
${ }^{1}$ A democracia participativa é aquela institucionalizada através de exercícios diretos de poder, como o plebiscito, o referendo e a inciativa popular. A democracia deliberativa é desenhada em um formato mais amplo e não institucionalizado. Nasce de diálogos sociais endógenos, sem formalismos ou molduras, acabando por interferir nas conformações políticas, sociais, econômicas, culturais e jurídicas de um determinado povo. Para o presente trabalho, democracia participativa e deliberativa são concebidas de forma diferente, apesar de se conceber que a democracia deliberativa inclui a democracia participativa, uma vez que não é possível deliberar sem antes ter participado.
} 
Desvelados os movimentos ideológicos do Direito, comprometidos com um "status quo" conservador das estruturas sociais e apresentando uma concepção de democracia não institucionalizada, fruto de diálogos sociais endógenos (democracia deliberativa), erige-se uma visão de Direito enquanto fato social, fenômeno coletivo, aplicável, tanto na teoria, quanto na prática, a partir de experiências culturais.

Quanto mais comprometido com seu meio coletivo, mais socializado será o Direito, alçado a um instrumento de organização social, ao mesmo tempo em que reflete as diferenças constantes entre os integrantes da teia social. Reflete uma sociedade aberta.

Este processo de socialização, de comprometimento aos valores do grupo, passa por uma aproximação, para não dizer por uma interação profunda, entre o fenômeno jurídico e a cultura enquanto razão explicativa de todo o contexto de uma determinada coletividade.

O Direito como objeto Cultural, resultado da implicação dialética de três elementos indissociáveis: fato, valor e norma, frutos da experiência humana histórica:

Direito é a concretização da ideia de justiça na pluridiversidade de seu dever ser histórico, tendo a pessoa como fonte de todos os valores.

...obedece a uma perspectiva do fato ('realização ordenada do bem comum'), da norma ('ordenação bilateral-atributiva de fatos segundo valores') e do valor ('concretização da ideia de justiça') (REALE, 2004, p. 67).

Esta concepção dará ao intérprete e aplicador da norma uma visão panorâmica de sua sociedade, preparando-se para que o saber jurídico sirva à coletividade e não o oposto. A análise da cultura, pois, é imprescindível para esta pretensão. O fenômeno cultural e seu alcance, notadamente em uma percepção de interculturalidade, é o ponto de partida e de chegada para se analisar o Direito moderno, inserto no ideal concreto de instrumental de democracia deliberativa.

A nova ordem intercultural parte, necessariamente, do reconhecimento de fenômenos globais de transposição de fronteiras regionais, literalmente, lançando o ser humano a uma sociedade culturalmente internacionalizada, concebida como uma nova comunidade exposta a diversidades de economias, políticas e, por conseguinte, de direitos, relendo conceitos tradicionais de nacionalismo e de soberania inflexíveis:

Resultados: cidades onde se falam mais de cinquenta línguas, tráfico ilegal entre países, circuitos de comércio travados porque o Norte se entrincheira em barreiras agrícolas e culturais, enquanto se despoja o Sul. As consequências 
mais trágicas: guerras "preventivas" entre países, dentro de cada nação e também no interior das megacidades. Militarizam-se as fronteiras e os aeroportos, os meios de comunicação e os bairros (GÁRCIA CANCILI, 2015, p. 17).

Fala-se do reconhecimento de "novas polis", não mais adstritas a peculiaridades próprias daqueles integrantes comunitários que se aproximam pelas identidades culturais semelhantes, concebidas como verdadeiros polos de diversidade, onde os seres humanos são insertos no mesmo espaço geográfico, porém influenciando e sendo influenciados pelas diversidades percebidas, em um processo que García Canclini denomina de "hibridação":

[...] Entendo por hibridação processos socioculturais nos quais estruturas ou práticas discretas, que existiam de forma separada, se combinam para gerar novas estruturas, objetos e práticas. Cabe esclarecer que as estruturas chamadas discretas foram resultado de hibridações, razão pela qual não podem ser consideradas fontes puras (GARCÍA CANCLINI, 2015, p. XIX).

Sistemicamente: a Cultura representa valores, frutos de histórias sociais abertas e libertárias. O Direito é formado pela implicação destes valores, a partir do reconhecimento de diversidades humanas e sociais, refletivas na sua exegese e aplicação. O Direito é, pois, plural.

Além de plural (o Direito) é fenômeno cultural, ou melhor, intercultural. Citando García Canclini (2015, p. 17):

O objeto de estudo muda. Em vez da cultura como sistema de significados, à maneira de Geertz, falaremos do cultural como 'o choque de significados nas fronteiras; como a cultura pública que tem sua coerência textual mas é localmente interpretada; como redes frágeis de relatos e significados tramados por atores vulneráveis em situações inquietantes; com as bases da agência e da intencionalidade nas práticas sociais correntes' (Ortner, 1999, p. 7).

Indo além, o reconhecimento da interculturalidade de nada adiantaria se não se pudesse almejar uma aplicação prática da realidade descrita, o que se dá, na visão defendida, através de uma atuação jurídica comprometida com a proposta formulada.

Busca-se um Direito plural e que se apresenta reflexo real de uma determinada sociedade, com suas características próprias, suas mazelas, seus encantos, suas verdades. Um Direito materializador de uma democracia deliberativa fruto das manifestações da própria coletividade, mediante seus diálogos intrínsecos e não institucionalizados. Um Direito cultural, ou seja, um Direito concebido, antes de qualquer outro formato, como força viva, social, dinâmico e, acima de tudo, interativo com seu meio. 
A cultura, como visto acima, é concebida em uma visão de conflito e interrelacionamento humano, onde cada indivíduo, detentor de experiências próprias e origens diversas se "misturam" em um processo constante de trocas e criatividade. Joaquín Herrera Flores (2007, p. 19) elucida:

Queremos resgatar a importância da arte para dinamizar nossa existência, pois seu compromisso radica a incitação constante ao movimento, ao deslocamento, à criatividade. [...] Por isso, toda manifestação artística de qualidade aporta sempre um componente político de contestação e de ativação de nossa capacidade de agir simbolicamente ao entorno das relações que vivemos.

A interculturalidade é um processo que atinge, também, o Direito em um viés plural que, a partir de seu alcance axiológico/valorativo, indica a difusão de pensamentos intrínsecos e extrínsecos ao seu sistema, este concebido de forma muito mais ampla do que a normativa. Ressalta-se a força dos princípios jurídicos gerais (não só os vigentes como direito posto) que funcionam como direito pressuposto, anterior a qualquer atividade legiferante.

\section{SAMBA DE ENREDO COMO INSTRUMENTO DE DEMOCRACIA DELIBERATIVA}

São várias as manifestações culturais de um povo. As fontes da cultura se originam das experiências humanas comunitárias, considerando comunidade, aqui, a união de entes subjetivos que se ligam por motivos ou objetivos comuns, tanto de natureza política, econômica, religiosa e, por obviedade, artística.

A comunidade está integrada em um conjunto maior de pessoas que, insertas em um determinado momento histórico e espaço geográfico, encontram-se em um mesmo contexto, apesar de diferentes objetivos e motivações. Este espaço geral é a sociedade.

As manifestações artísticas, no caso o gênero musical "samba de enredo", surgem voluntariamente em comunidades, geralmente periféricas de várias cidades do país que, motivadas pelo som ritmado dos instrumentos de percussão e por letras cotidianas, formam rodas de batuque que servem, tanto para socialização das pessoas, quanto para disseminar a cultura local. 
Aqui, desde já se esclarece, dá-se ênfase ao samba carioca e seus desmembramentos. A escolha deste gênero musical vem refletir a possibilidade de, através de uma manifestação cultural artística, teoricamente nascida de comunidades não oficiais, ser capaz de influenciar a condução política, social e jurídica de determinada sociedade.

$\mathrm{Na}$ medida em que se reconhece manifestações interculturais como formas de poder político (democracia deliberativa) acaba, por consectário, a se reconhecer um Direito também interculturalizado que se manifestará, tanto em sua aplicação, quanto na sua construção legislativa, almejando validade efetiva, social e ética. Um Direito comprometido axiologicamente com sua sociedade, deixando de ser mero aparato legal, muitas vezes a serviço de uma exegese conservadora; inibidora do seu dinamismo próprio.

Em matéria de sambas de enredo, observam-se verdadeiras incursões nos problemas da coletividade, desvelando-os e apresentando pretensões que acabaram por interferir na forma de conduzir a sociedade organizada. Neste diapasão, há sambas de enredo contestadores e críticos do "status quo", ao mesmo tempo em que apresentam alternativas para problemas constatados e “abandonados” pelo "poder central”, político, social e, é claro, jurídico.

O samba de enredo é, portanto, uma alternativa ao exercício oficial de formas de democracias participativas, no ponto que, refletindo um pensamento de comunidades através da escolha de uma temática própria para o carnaval, desenvolve uma ideia capaz de interferir na transformação societária.

Não são, obviamente, todos os sambas de enredo que podem ser encarados como exercício real de cidadania direta, mas sim aqueles contestadores da ordem vigente e formadores de opinião.

As letras dos sambas, hoje, reconhecem-se, cada vez mais vinculadas às exigências das escolas de samba que apresentam um enredo prévio e exigem adaptação das letras da música a tal, não deixam de ser interessantes do ponto de vista democrático e plural.

Para usar apenas as escolas de sambas de grupo especial, observam-se desde temáticas ecológicas, de crítica à degradação do meio ambiente (“Como era Verde meu Xingu”, Mocidade Independente de Padre Miguel - 1983), passando por denúncias econômicas e de submissão ao capital externo (“Assombrações”, União da Ilha do Governador - 1985), ao tema do preconceito ("Kizomba - Festa da Raça" - Vila Isabel - 1988), do poderio econômico na cultura ("Ratos e Urubus, larguem a minha fantasia" - Beija Flor de Nilópolis - 1989) e, claro, até as mazelas sociais com o celebrado "E por falar de saudade", Caprichosos de Pilares, 1985. 
O samba de enredo democratizou a democracia. Com as demonstrações culturais citadas, podemos conceber um pluralismo jurídico democrático, a partir de novas formas de se criar o direito, a partir de experiências democráticas concretas. Fazer uma construção crítica do fenômeno jurídico-social:

Justifica-se, assim, conceituar "teoria jurídica crítica" como a formulação teórico-prática que se revela sob a forma do exercício reflexivo capaz de questionar e de romper com o que está disciplinarmente ordenado e oficialmente consagrado (no conhecimento, no discurso e no comportamento) em dada formação social e a possibilidade de conceber e operacionalizar outras formas diferenciadas, não repressivas e emancipadoras, de prática jurídica (WOLKMER, 2001, p. 18).

A análise do samba de enredo como espaço cultural de exercício de uma democracia deliberativa e de pluralidade jurídica insere-se na própria discussão científica do fenômeno estudado. A música, como tantas outras manifestações artísticas, faz parte da cientificidade social, encontrando-se nela elementos próprios de "ciência".

Ciência que considera como forma de pensar um determinado fato emergido da sociedade e seus reflexos no contexto social como um todo, influenciando pensamentos e assunção de posições claras, hábeis a modificar um cenário estabelecido.

O samba de enredo, inserto no carnaval enquanto maior festa popular do País, tem cientificidade necessária para gerar investigação e análise tematizada de seus efeitos, ainda que, impossíveis de entabulação completa dos resultados, já que obviamente, não está situado na órbita das ciências exatas. Em interessante obra, Alessandro Cury Soares e Rochele de Quadros Loguércio tratam da "ciência no universo da folia" asseverando:

Assim, mais do que conceituá-la, interessa-nos pensá-la como cultura, dado que a ciência está no sentido lato na sociedade, sem quaisquer esforços para que se difunda, para que exista, para que permaneça, ela aí está, na base de nossa cultura. Tem efeitos no mundo, quer nós a interpretemos, conceituemos, identifiquemos ou não. Estamos em um mundo em que é impossível se pensar viver fora do conhecimento científico. Ele se torna, então, uma forma de percebermos o mundo (SOARES; LOGUÉRCIO, 2017, p. 26).

E indo além, comentam, com a simplicidade dos fatos cotidianos da vida, a codificação de manifestações culturais que, popularmente, trazem elementos teóricos e empíricos: 
Não há possibilidade de estarmos no mundo sem estarmos inseridos nessa cultura. Não precisamos nos esforçar para viver a ciência, pois ela simplesmente ali está, como tecnologia na maioria das vezes: no creme dental, na água do chuveiro, no próprio chuveiro, em macro e micro espaços de nosso cotidiano. Porém, mesmo que não oculta, tampouco ela está visível. A ciência precisa das fulgurações que constroem seu saber e, em cada lugar que habita, ou ela é idolatrada ou é interditada (SOARES; LOGUÉRCIO, 2017, p. 26).

Então, por que não o samba de enredo das escolas de samba do grupo especial do Rio de Janeiro (eleito pelo caráter influenciador deste gênero nas demais agremiações carnavalescas nacionais) pode ser instrumento científico cultural de promoção de democracia, caracterizada como instrumental de concretização dos direitos humanos?

O foco da pesquisa é, repita-se, o samba de enredo como expressão de democracia plural e deliberativa, fenômeno interculturalizante, insurgente, emancipatório e questionador.

Acredito que o gesto inaugural de uma prática democrática consista no reconhecimento da legitimidade do conflito na sociedade. Entretanto, para que exista tal gesto, precisamos contar não só com os governantes que a admitam, mas também com uma sociedade questionante e desmistificadora dos eufemismos donde emerge o mito da unidade; o mito de um dever uniformizado como virtualidade permanente, incapaz de acolher a fragmentação, a polifonia dos costumes, das crenças e dos desejos que fazem as experiências do mundo (WARAT, 2000, p. 31).

Neste contexto, abaixo, se elenca um exemplo de obra que demonstra, cabalmente, a possibilidade de um samba de enredo atingir a sociedade difusa e influenciar sua modificação e movimentos de insurgência, refletindo no Direito as suas nuances.

A Estação Primeira de Mangueira, dentro da concepção que este trabalho defende, fez um samba de enredo antológico no Carnaval de 2019. O samba de autoria de Tomaz Miranda, Ronie Oliveira, Márcio Bola, Mamá, Deivid Domenico e Danilo Firmino serviu de base musical para o enredo "História pra ninar gente grande" do carnavalesco Leandro Vieira e que repercutiu mundialmente dada a visibilidade do carnaval carioca:

Lastreado no samba-enredo como ritmo musical, o Carnaval carioca funciona no seu habitat, o eixo Rio-São Paulo, e, embora, tenha hoje uma festa de rua com ampla participação popular, realizada por centenas de blocos, o desfile das tradicionais escolas de samba continua mantendo o Rio de Janeiro como a imagem internacional do Carnaval do Brasil (PIPOLO, 2019, p. 73). 
A ideia contida no enredo mangueirense é, justamente, demonstrar a existência de poderes periféricos emissores ou produtores de formas alternativas de comando societário, desmistificando o poder central oficial que apresenta somente sua versão dos fatos históricos como a única verdadeira, posto que contada pelos vencedores.

Analisando a sinopse do enredo, observam-se aspectos de verdadeira democracia deliberativa, ao passo que se propõe a análise da história do Brasil sob outro ângulo, qual seja, o da maioria silenciosa, normalmente, sem efetiva representação:

HISTÓRIA PRA NINAR GENTE GRANDE é um olhar possível para a história do Brasil. Uma narrativa baseada nas páginas ausentes.

[...]

Da forma geral, a predominância das versões históricas bem-sucedidas está associada à consagração de versões elitizadas, no geral, escrita pelos detentores do prestígio econômico, político militar e educacional [...] (SRZD, 2019).

O samba de enredo do GRES Estação Primeira de Mangueira é exemplo vivo da interculturalidade aqui defendida e de seus reflexos no Direito concebido em um panorama de pluralidade de fontes produtoras do fenômeno jurídico que não, apenas, o Estado legiferante. Um direito que nasce de "movimentos intrassocietários", espontâneos ou organizados, que produzem comportamentos e ideologias próprias, em leituras, na maioria das vezes, diversas do pensamento oficial dominante:

Questões como a diferença e a multiculturalidade têm sido incorporados para a construção da própria identidade dos movimentos. Lutam pelo reconhecimento da diversidade cultural. Há neles na atualidade, uma ressignificação dos ideais clássicos de igualdade, fraternidade e liberdade (GOHN, 2013, p. 21).

A Mangueira ao propor "recontar" a história do Brasil, dando ênfase às pessoas “comuns" e não aos líderes "vencedores", pretende demonstrar que a construção de uma nação transborda os limites desenhados por aqueles que, em determinados momentos, assumiram a posição de "poder central", a partir do qual são traçadas as políticas públicas e, por consequência, o próprio direito. Gándara Carballido comenta esta nuance a partir da temática direitos humanos:

Lo mismo ocorre com la construcción de las historias oficiales sobre los derechos humanos. Se ofrece uma comprensión de tal historia según la cual son importantes solo ciertos hitos (las revoluciones americana y francesa, la 
firma de la Declaración Universal de los Derechos Humanos, elaboración de las diversas cartas de derechos, por ejemplo), pero no así las luchas populares de liberación (la lucha por la tierra de los pueblos del sur y las luchas de resistencia de comunidades indígenas y afrodescendientes, también por ejemplo). Mucho menos tales historias oficiales ponen em evidencia las acciones abiertamente contrarias a los derechos humanos llevadas adelante por las potencias hegemónicas (GÁNDARA CARBALLIDO, 2013, p. 17-18)

O samba sob análise é transparente ao indicar a formação cultural do povo brasileiro a partir de experiências pessoais vividas em diversas partes de seu território, em determinados momentos ou períodos históricos, que influenciaram democraticamente a condução do próprio País, mesmo que, sub-repticiamente, o poder central assuma a autoria destes movimentos. A sinopse da Estação Primeira de Mangueira desnuda tais fatos:

Não à toa que o termo 'DESCOBRIMENTO' ainda é recorrente quando, na verdade, a chegada de Cabral às terras brasileiras representou o início de uma 'CONQUISTA'. E, ao ser ensinado que foi 'descoberto' e não 'conquistado', o senso coletivo da 'nação' jamais foi capaz de se interessar ou dar o devido valor a cultura indígena, associando-a 'a programa de gosto duvidoso' ou comportamentos inadequados, vistos como 'vergonhosos' (SRZD, 2019)

A força deliberativa, democrática e intercultural do samba de enredo da Mangueira em 2019 está na demonstração cabal de que os rumos de um País são direcionados pela sociedade comum, não necessariamente organizada em partidos políticos ou através de representantes eleitos, cada vez mais, distantes dos seus eleitores. A força do samba está na comprovação de que a sociedade e o seu direito são frutos de um verdadeiro pluralismo jurídico, hábil a influenciar a aplicação e a construção jurídicas cotidianas.

Antonio Carlos Wolkmer esclarece:

[...] uma alternativa frente a este tipo de tradição (legal, liberal conservadora) implica em romper com a matriz jurídica burguês-capitalista, construindo um outro referencial teórico prático, engendrado através de um novo saber jurídico e de uma nova racionalidade (WOLKMER, 1996, p. 193).

A ideia contida na obra artística da Estação Primeira de Mangueira é a de superar os processos tradicionais de construção social, política, educacional e jurídica comprovando a viabilidade do exercício de poder pela sociedade, através de seus integrantes e de suas experiências e práticas reais: 
[...] Tal opção consiste em redefinir os processos de racionalização que não nascem mais dos a priori fundantes universais, mas da contingência direta das necessidades humanas fundamentais geradas pelas práticas sociais cotidianas (WOLKMER, 1996, p. 194).

Não se pode esquecer que o samba mangueirense de 2019 enfrentou questões submersas e escondidas nos porões da história brasileira, indicando como único caminho a seguir, a radicalidade democrática que nasce "da atuação de "gente comum" que sabe suas origens, seus heróis anônimos, seu passado (muitas vezes abominável) e seu futuro intercultural, plural e libertador (MIRANDA; OLIVEIRA; BOLA; MAMÁ; DOMÊNICO; FIRMINO, 2019):

Mangueira, tira a poeira dos porões

São verde e rosa, as multidões

Brasil, meu nego

Deixa eu te contar

A história que a história não conta

$\mathrm{O}$ avesso do mesmo lugar

Na luta é que a gente se encontra

$[\ldots]$

Brasil, meu dengo

A Mangueira chegou

Com versos que o livro apagou

Desde 1500 tem mais invasão do que descobrimento

Tem sangue retinto pisado

Atrás do herói emoldurado

Mulheres, tamoios, mulatos

Eu quero um país que não está no retrato

[...]

Salve os caboclos de julho

Quem foi de aço nos anos de chumbo

Brasil, chegou a vez

De ouvir as Marias, Mahins, Marielles, Malês.

Um ponto que merece comentários dentro dos objetivos contidos no samba de enredo da Mangueira de 2019 e que acabou refletindo em atitudes concretas dos poderes instituídos do País diz respeito à menção na letra da obra musical à vereadora carioca morta em 2018, Marielle Franco, política, graduada em Ciências Sociais, mestre em administração pública e socióloga.

A citação a Marielle no samba de enredo juntamente com outras personagens, assumidamente revolucionárias de seu tempo, como Luísa Mahin (articuladora das revoltas abolicionistas na Bahia do Século XIX) e Dandara (face feminina do quilombo de Palmares), demonstra a necessidade de se compreender a história de um País a partir de manifestações 
realizadas em meio a determinadas coletividades que, com espírito de rebeldia, defenderam ideais de liberdade e igualdade, sendo que, mesmo sufocadas em um primeiro momento, propiciaram o "germinar" de novos pensamentos e transformações.

No caso específico de Marielle, ligada a pautas de apoio aos direitos das mulheres, à população LGBT, aos familiares de vítimas de homicídios, inclusive policiais, dentre outros assuntos pertinentes à defesa dos direitos humanos e cidadania, a morosidade na apuração dos responsáveis por seu assassinato (e de seu motorista Anderson Pedro Gomes), fez com que a Estação Primeira de Mangueira, em exercício de democracia deliberativa, exigisse do poder central condutas reais de persecução penal, demonstrando que o Estado não é, necessariamente, a única fonte de medidas políticas, jurídicas ou sociais esperadas, mas sim, apenas, o canal instrumental para materialização dos anseios humanos nascidos no interior do tecido coletivo.

A repercussão do samba de enredo da Mangueira, campeã do Carnaval Carioca do Grupo Especial de 2019, foi enorme e, por que não dizer, eficaz. Em 12 de março de 2019, uma semana após a proclamação do campeonato Mangueirense, foram presos dois suspeitos de participação no crime à vereadora. Evidente resposta aos clamores nascidos da sociedade ou mera coincidência?

\section{CONSIDERAÇÕES FINAIS}

Tudo que se pretende elaborar envolvendo temáticas de efetiva participação social na condução dos rumos políticos e jurídicos de uma determinada coletividade é, necessariamente, pautado em processos de agregação de experiências dinâmicas e evolutivas, não podendo se basear em movimentos estanques e limitados.

A sociedade é fruto da gregariedade humana, ou seja, da própria concepção do "humano", enquanto ser anímico, que busca em seus semelhantes o atendimento das mais diversas necessidades e dos mais comezinhos objetivos. Estes escopos variam conforme o grau de desenvolvimento, dependência ou independência societárias, frente a determinados contextos históricos e geográficos.

A humanidade se liga, ou melhor, entrelaça-se, a partir de diálogos múltiplos que refletem as diferenças e identidades culturais dos integrantes de uma coletividade, tanto considerada em seu aspecto local, regional, quanto em um aspecto global, universal. A 
formação do tecido social nasce a partir de "camadas", muitas vezes indefinidas, localizadas, conforme o viés analisado, mais próximas ou distantes dos centros de poder instituídos.

Os centros de poder, aqui detectados, são aqueles que reproduzem uma ideologia "vencedora", ou seja, detentores de poder político e econômico que, se utilizando do aparato do Estado, inclusive legislativo e judicial, conduzem o formato de pensamento do todo coletivo, visando à conservação da desequilibrada estrutura social, mantendo-se o "status quo" e impondo uma eternização do período histórico vigente.

Revela-se, assim, a existência de uma "periferia social", distante da centralidade dominante, mas que, em um processo dialógico, difuso e não institucionalizado, é foco produtor de cultura hábil a influenciar a condução dos destinos de um determinado povo.

A análise do elemento "cultura", reconhecida como qualquer manifestação social fruto das experiências de uma determinada coletividade, parte da necessária desconsideração do tradicionalismo que, sob a argumentação "politicamente correta" ou "pseudo-neutra", apregoa a defesa do "multiculturalismo" como suficiente para "reconhecer e respeitar as diferenças", quando, na verdade, acaba por sedimentá-las.

Neste sentido, "cultura" vem desenhada como fenômeno muito mais complexo que o acatamento do "oposto" e sim como força de interação entre os diversos em um processo denominado de "interculturalidade", compreendida como implicações de visões que, ao mesmo tempo em que se chocam e, aparentemente, repelem-se, complementam-se formando pela tensionalidade, uma sociedade ampla, aberta e plural.

Somente se permite reconhecer a interculturalidade se desconstruirmos ideologias e modelos estáticos de estruturação societária, calcados em limites econômicos, políticos e jurídicos de acesso pleno aos valores almejados pela pessoa humana, enquanto destinatária de direitos. Direitos humanos concebidos como valores fontes de todos os valores materializados através da oferta de condições concretas (empíricas) e abstratas de acesso a bens e outros instrumentos de implementação de dignidade.

O Direito, como instrumental sufragador desta interculturalidade, tende a superar seu uso condicionado pelos centros de poder que o caracterizam como marcado por um exacerbado formalismo técnico, por uma exegese ou hermenêutica tímidas, pelo apego a um dogmatismo cego e avalorativo, pela defesa da neutralidade do intérprete, com secundarização de princípios gerais e pelo congelamento de determinado momento temporal. Defende-se, pois, um fenômeno jurídico nascido do enlace de três polos atrativos - fato, valor e norma - que se 
implicam dialeticamente, surgidos de movimentos sociais des (organizados), difusos na coletividade e capazes de edificá-lo em formato pluralista, aberto, axiológico e, principalmente, insurgente. Defende-se, portanto, a existência de um Direito plural e democrático.

A proposta é a defesa de uma democracia deliberativa que rompe as molduras preconcebidas pelo direito posto, seja de natureza constitucional, seja de natureza infraconstitucional. Uma democracia que nasce do diálogo endógeno das comunidades periféricas que debatem, constroem, argumentam, contra-argumentam e decidem sobre pontos de seus reais interesses e necessidades, conduzindo-se política e culturalmente, fazendo, enfim, Direito.

A democracia deliberativa é, pois, definida como mecanismo de humanização e descentralização do Direito, que pode nascer ou ter como fontes condutas intersubjetivas "extraoficiais" e não apenas atitudes estatais, legalistas e fundadas em processos legiferantes instrumentalizados. Um Direito nascido das ruas; da periferia marginalizada; dos guetos e comunidades "esquecidas; das artes espontâneas e "sem catalogação formal", enfim, do povo.

Neste contexto, democracia deliberativa e interculturalidade são aspectos indissociáveis para a compreensão do Direito como fenômeno plural, crítico, axiológico e comprometido com a maioria silenciosa da sociedade. Somente um direito intercultural tem possibilidade de atender aos anseios de uma coletividade, reconhecendo-se em diversas manifestações artísticas, espontaneamente, frutos das experiências de um povo.

Como arte que é, o samba de enredo, encarado a partir de manifestações interculturais e difusas socialmente, é apresentado como forma instrumental de "deliberação democrática" hábil a garantir, através de ações ativas das comunidades, os direitos humanos e expectativas próprias de seus integrantes que são, enfim, reconhecidos e individualizados, sobressaindo-se da "massa" conduzida e sufocada.

A análise do samba de enredo foi realizada sob aspecto de edificação de ideias e conceitos enquanto frutos da criatividade de um agrupamento social que, sob um ritmo musical brasileiro, com origens africanas, se auto organiza, desenvolvendo "estórias e histórias", hábeis a influenciar a própria vida de seus integrantes. O samba de enredo pode, através de suas letras, ser considerado instrumento de democracia deliberativa, estimulando, inclusive, a produção legislativa nacional, na medida em que aborda temáticas, até então, dolosamente, esquecidas pelo centro do poder. Verificam-se, neste contexto, sambas que abordam a questão do direito à 
moradia, direitos sociais, direitos de locomoção, direitos da personalidade, dentre outros valores almejados pela coletividade.

O samba de enredo, além do viés de construção de objetivos sociais de um grupo, também, é usado como "voz da maioria silenciosa", periférica e distante das decisões políticas. Comuns, neste diapasão, a existência de obras que denunciam condutas omissas dos poderes instituídos, desvios comportamentais de agentes detentores de poderes, ineficiência da máquina pública, a pseudoneutralidade do Poder Judiciário, o "cerrar dos olhos" aos criminosos protegidos pelo poder central, enfim, os desmandos que sedimentam as desigualdades, estratificam a sociedade em classe e subclasses, desumanizando pessoas, ou pior, as coisificando.

Apesar de muitos caminhos tortuosos por que percorreram os sambas de enredo das agremiações carnavalescas cariocas, o certo é que o foco deste trabalho esteve no reconhecimento daquele como arte e cultura plural, repleto de conteúdo democrático e democratizante, atuando como força viva e dinâmica de ruptura do "status quo" conservador e oligárquico, funcionando como "moldura revolucionária" aos movimentos de deliberação que podem influenciar um momento histórico e social, levando toda a coletividade (e não só parte dela) à plenitude de direitos humanos, enquanto "apoteose" democrática.

\section{REFERÊNCIAS}

ALLEBRANDT, Sérgio Luís; AGOSTINI, Cíntia. A democracia participativa e deliberativa e sua importância para qualificar o processo de planejamento do desenvolvimento regional. Data: maio 2015. Disponível em: <http://researchgate.net/publication/307877687_A_Democracia_Participativa_e_Deliberativa_ e_sua_importância_para_qualificar_o_processo/de_Planejamento_do_Desenvolvimento_Regional>. Acesso: em: 15 ago. 2019.

AVRITZER, Leonardo. Prefácio. In: LEAL, Rogério Gesta (Org). A democracia deliberativa como nova matriz de gestão pública: alguns estudos de casos. 1.ed. Santa Cruz do Sul: Edunisc, 2011.

GÁNDARA CARBALLIDO, Manuel Eugenio. Repensando los derechos humanos desde las luchas. Revista Eletrônica do Tribunal Regional do Trabalho da 9a Região. Curitiba, Pr, v. 2, n. 24, p.17-18, out. 2013.

GARCÍA CANCLINI, Néstor. Culturas híbridas. 4. ed. $7^{\mathrm{a}}$ reimpressão. São Paulo: Edusp, 2015, p. XIX. 
GOHN, Maria da Glória. Movimentos sociais e redes de mobilizações civis no Brasil contemporâneo. Petrópolis: Vozes, 2013.

HERRERA FLORES, Joaquín. A (re) invenção dos direitos humanos. Florianópolis: Fundação Boiteux/IDHIS, 2009.

HERRERA FLORES, Joaquín. O nome do riso. Tradução de Nilo Kaway Junior. Porto Alegre: Movimento, 2007.

MIRANDA, Tomaz; OLIVEIRA, Ronie Oliveira; BOLA, Márcio; MAMÁ; DOMÊNICO, Deivid; FIRMINO, Danilo. Samba-Enredo 2019. Histórias para ninar gente grande. G.R.E.S. Estação Primeira de Mangueira (RJ). Disponível em: $<$ https://www.letras.mus.br/mangueira-rj/samba-enredo-2019-historias-para-ninar-gentegrande/>. Acesso em: 10 set.2019.

PIPOLO, Otto. Sistema jurídico aplicado ao carnaval e às demais manifestações culturais: Teoria, prática e jurisprudência. São Paulo: All Print, 2019.

REALE, Miguel. Lições preliminares de direito. 27.ed. São Paulo: Saraiva. $4^{\text {a }}$ tiragem, 2004.

SEN, Amartya. Desenvolvimento como liberdade. $5^{\text {a }}$ reimpressão. São Paulo: Companhia das Letras, 2016.

SOARES, Alessandro Cury; LOGUÉRCIO, Rochele de Quadros. A ciência no universo da folia. 1. ed. Curitiba: Appris, 2017.

SRZD. Sinopse enredo Mangueira. Disponível em: <https://www.srzd.com/carnaval/rio-dejaneiro/sinopse-enredo-mangueira-carnaval-2019/acesso>. Acesso em: 11 set. 2019.

STRECK, Lenio Luiz. Jurisdição constitucional e hermenêutica. Uma nova crítica do direito. 2. ed. Rio de Janeiro: Forense, 2004.

WARAT, Luis Alberto. A Ciência Jurídica e seus dois maridos. 2. ed. Santa Cruz do Sul: Edunisc, 2000.

WOLKMER, Antonio Carlos. A construção democrática do direito: Estado, desobediência civil e ética. In: ARGUELLO, Kattie. Direito e Democracia - entrevista. Florianópolis: Letras Contemporâneas, 1996.

WOLKMER, Antonio Carlos. Introdução ao pensamento jurídico crítico. 3. ed. São Paulo: Saraiva, 2001.

WOLKMER, Antonio Carlos. Pluralismo jurídico: Fundamentos de uma nova cultura no Direito. 3. ed. São Paulo: Alfa Ômega, 2001, p. 170. 